\title{
Symptoms of Diabetes ${ }^{1}$
}

\author{
Linda B. Bobroff ${ }^{2}$
}

Type 2 diabetes is a growing health concern for children as well as adults in the United States. Diabetes that is uncontrolled can lead to blindness, kidney disease, heart disease, and amputations. Early treatment to control blood glucose levels helps decrease a person's chances of developing these health problems. Everyone should be tested for diabetes at their regular checkups. If you have any of the following symptoms of diabetes, see your health care provider right away! (Remember, sometimes type 2 diabetes has no symptoms.)

Increased urination. If you are urinating either more often or in greater amounts than normal, it may be caused by high blood sugar.

\section{Excessive thirst or hunger. If you are} thirsty more often than normal, or if you can't satisfy your thirst, this may be a symptom of

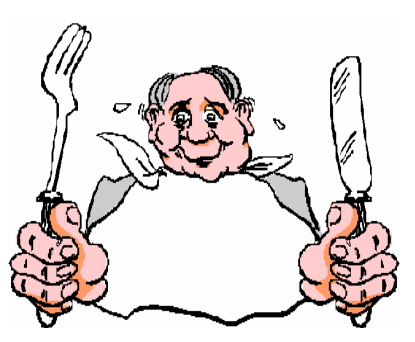
diabetes. Some people with untreated diabetes feel like eating all the time; their appetite is greater than normal for them.

Weight loss. Losing weight quickly without trying to could be a symptom of diabetes.
Fatigue. High blood glucose levels can make you feel tired. If you are more tired than usual, and changes in your lifestyle are not the

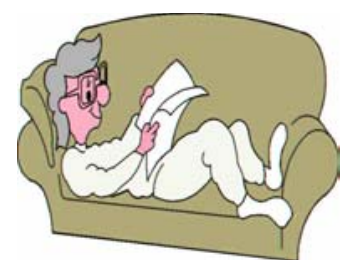
cause, it may be a sign of diabetes.

Wounds that don't heal. Untreated diabetes can cause poor wound healing. Watch for infections or cuts that don't heal in a reasonable amount of time after using first aid.

Blurred vision. This may be a sign that you need new glasses, or it might be a symptom of early eye disease due to diabetes.

1. This document is FCS8751, one of a series of the Department of Family, Youth and Community Sciences, Florida Cooperative Extension Service, Institute of Food and Agricultural Sciences, University of Florida. Publication date: February 2005. Please visit the EDIS Web site at http://edis.ifas.ufl.edu

2. Linda B. Bobroff, PhD, RD, LD/N, professor, Department of Family, Youth and Community Sciences, Cooperative Extension Service, Institute of Food and Agricultural Sciences, University of Florida, Gainesville, 32611. Reviewed by Jennifer Hillan, MSH, RD, LD/N, Glenda L. Warren, MS, RD, CFCS, University of Florida, Sharon C. Valley, MS, CDE, University of Florida/Shands Diabetes Center, and Nancy J. Gal, MS, Marion County Extension Service. 